\title{
BROODING BEHAVIOR IN A NON-AVIAN DINOSAUR, OVIRAPTOR (THEROPODA, OVIRAPTORIDAE)
}

NORELL*, Mark A., Vertebrate Paleontology Department, American Museum of Natural History, 79th St. @ CPW, New York, NY 10024, U.S.A.; CLARK, James M., Biological Sciences Department, George Washington University, Washington, DC 20052, U.S.A.; CHIAPPE, L.M., Ornithology Department, American Museum of Natural History, 79th St. @ CPW, New York, NY 10024, U.S.A.

The initial discovery in 1923 of Oviraptor philoceratops overlying a nest of eggs at the Flaming Cliffs was interpreted by its describer, Henry Fairfield Osborn, as a case of a predator caught in the act of robbing a nest. A series of remarkable discoveries by the American Museum of Natural History - Mongolian Academy of Sciences expeditions to the Gobi Desert of Mongolia now demonstrate that this instead provides evidence of avian-like parental care in this species of theropod dinosaur. Specimens from the newly discovered locality at Ukhaa Tolgod comprise some of the best evidence yet of reproductive behavior in any non-avian dinosaur.

Discovered in 1993, Ukhaa Tolgod exposes outcrops primarily of eolian sandstones interbedded with fluvial siltstones and sandstones, with a Late Cretaceous fauna similar to that of the Djadokhta Formation at the Flaming Cliffs. It is among the richest Mesozoic vertebrate localities in the world, and is the richest for mammals and lizards, as measured by the number of articulated skulls it has produced in only three years of collecting. Unlike the deposits at the Flaming Cliffs, however, protoceratopsians are rare while Oviraptor and related taxa are relatively abundant.

Dinosaur eggs are common in Djadokhta and correlative deposits, but the identity of the various types of eggs has been enigmatic without the definitive evidence provided by embryos. An oviraptorid embryo discovered in 1993 provides the crucial evidence linking one particular type of egg with this taxon. The distinctive shape, sculpturing, and histology of the egg shell identify it as the type that is most common at the Flaming Cliffs. More important, it is the type of egg in the nest over which the first specimen of Oviraptor philoceratops was found. The identification of the eggs with the same taxon as the adult overlying them suggests that the adult may have been a relative tending the nest, rather than a predator eating it. More compelling evidence that this is indeed the case is provided by a specimen discovered overlying a nest at Ukhaa Tolgod.

The Ukhaa Tolgod skeleton lacks a skull and most vertebrae, but all four limbs are preserved in exceptional detail. Their relationships to the eggs demonstrate that the body was not sprawled haphazardly over the nest, but rather was positioned directly over the center with the limbs placed symmetrically. Furthermore, the posture is nearly identical to that taken by living birds when they brood their nests (i.e., sit on the nest). The simplest interpretation of this specimen is that the adult died while brooding the nest.

Parental care of nests is a feature common to both crocodylians and birds, and it is therefore to be expected in descendants of their common ancestor such as Oviraptor. Crocodylians do not brood their nests, however, and this behavior must have evolved along the lineage leading to birds from their common ancestor with crocodylians. The new specimens, and others as yet unprepared, provide evidence that this behavior evolved within the Theropoda before the evolution of avian flight. 